\title{
Pathogenic analysis of Borrelia garinii strain SZ isolated from northeastern China
}

\author{
Qiong Wu, Zhijie Liu, Jidong Wang, Youquan Li, Guiquan Guan, Jifei Yang, Ze Chen, Jianxun Luo* and Hong Yin
}

\begin{abstract}
Background: Various genospecies of Borrelia burgdorferi sensu lato (s.l.) have been identified from patients and animals worldwide. Genospecies-related dissemination of disease has been reported. The present study aimed to elucidate the pathogenicity of infections caused by B. garinii SZ isolated in China. B. burgdorferi B31 and B. afzelii BO23 were used for comparison.

Methods: Spirochete load in blood and tissue samples of infected mice were measured by minor groove binder-based real-time polymerase chain reaction. The kinetics of spirochete dissemination and disease severity were assessed in BALB/c mice.

Results: The pattern of bacterial load differed between the three genospecies. The B. garinii SZ strain is highly pathogenic and can trigger multi-system pathological damage in mice.

Conclusions: Spirochete dissemination, persistence, tissue tropism and disease severity varied significantly, suggesting that different genospecies may play an important role in the pathogenicity and development of clinical diseases.
\end{abstract}

Keywords: B. burgdorferi, Pathogenicity, Kinetics of spirochete, Disease severity

\section{Background}

The Borrelia burgdorferi s.l. complex comprises 18 known Borrelia genotypes. Three of them predominate as human pathogens: B. burgdorferi sensu stricto (s.s.), $B$. garinii (including B. garinii OspA type 4, recently designated B. bavariensis) and B. afzelii [1]. However, $B$. valaisiana, B. lusitaniae, B. spielmanii and B. bissettii, have been also occasionally isolated or detected in patient specimens $[2,3]$. The symptoms and severity of the disease vary in $B$. burgdorferi genospecies. B. garinii is primarily associated with neuroborreliosis [4], B. afzelii with acrodermatitis chronic athrophicans [5] and $B$. burgdorferi s.s is prevalent in Lyme arthritis [6].

Examination of the relationship between genospecies and clinical symptoms using real-time polymerase chain reaction (PCR) to detect $B$. burgdorferi levels in all tissues of $\mathrm{C} 3 \mathrm{H} / \mathrm{HeJ}$ mice and $\mathrm{BALB} / \mathrm{c}$ mice reported a positive correlation between clinical symptoms (arthritis)

\footnotetext{
* Correspondence: ljxbn@163.com; yinhong@caas.net.cn

State Key Laboratory of Veterinary Etiological Biology, Key Laboratory of Veterinary Parasitology of Gansu Province, Key Laboratory of Grazing Animal Diseases MOA, Lanzhou Veterinary Research Institute, Chinese Academy of Agricultural Science, Lanzhou 730046, China
}

and spirochete burden [7]. The correlation of $B$. burgdorferi genospecies with clinical presentation is potentially valuable in explaining the disease manifestations of Lyme borreliosis [8]. Numerous new isolates of $B$. burgdorferi have been obtained. However, the pathogenicity of these isolates is unclear.

B. garinii is the main genotype found in China [9]. To elucidate the pathogenicity of the B. garinii SZ isolated in China, the kinetics of spirochete dissemination and the severity of the disease were evaluated in a murine model. Considering that different genotypes of $B$. burgdorferi could potentially affect disease pathogenicity, B. burgdorferi $\mathrm{B} 31$ and B. afzelii $\mathrm{BO} 23$ were used for comparison. Dissemination of spirochetes in blood and tissues was evaluated using TaqMan ${ }^{\mathrm{Tm}}$ minor groove binder (MGB) - real time polymerase chain reaction (PCR) and disease severity was assessed by histopathologic assessment of inflammatory cell infiltrates and the extent of tissue necrosis.

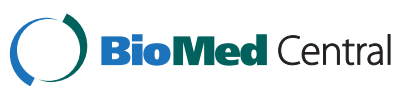

(c) 2013 Wu et al.; licensee BioMed Central Ltd. This is an Open Access article distributed under the terms of the Creative Commons Attribution License (http://creativecommons.org/licenses/by/2.0), which permits unrestricted use, distribution, and reproduction in any medium, provided the original work is properly cited. 


\section{Methods}

\section{Bacterial strains}

B. burgdorferi B31 and B. afzelii BO23 were purchased from ATCC (Manassas, VA) and were passaged five times in vitro. B. garinii SZ was isolated from Dermacentor ticks collected in Shangzhi County of Heilongjiang Province, China [10]. These strains were incubated in BSK-H medium at $33^{\circ} \mathrm{C}$ and observed with a dark-field microscope every other day. The bacteria were harvested by centrifugation at 5,000 g when they reached logarithmic phase and were washed twice with phosphate buffered saline (PBS). The suspension was adjusted to a density containing $10^{5}$ cells $/ \mathrm{ml}$ using a Petroff-Hausser counting chamber.

\section{Mice and infection}

Female specific pathogen-free BALB/c mice were obtained from the Breeding Laboratory, Lanzhou Veterinary Research Institute (Lanzhou, China). All mice were 4 weeks old at the time of infection. The mice were divided randomly into control, SZ, BO23 and B31 groups each consisting of 25 mice. Mice in the experimental groups received an intraperitoneal injection of $200 \mu \mathrm{l}$ PBS containing $10^{5} / \mathrm{ml}$ of $B$. burgdorferi cells in experimental groups. Control mice were injected with $200 \mu \mathrm{l}$ PBS. Tissue specimens from blood, brain, tongue, heart, lung, liver, spleen, kidney, lymph, bladder, joints and skin were collected on days 2, 5, 9, 15, 30, 60, 90 and 150 after infection.

\section{DNA preparation}

DNA was prepared using the QiaAmp tissue kit and Puregene blood core kit (Qiagen, Valencia, CA) following the manufacturer's instructions. The DNA was finally eluted in $200 \mu \mathrm{l}$ distilled water and stored at $-20^{\circ} \mathrm{C}$ until use.

\section{Real-time PCR}

Simultaneous detection and quantification of $B$. burgdorferi DNA were performed in a model MX3000 P real-time PCR machine (Stratagene, La Jolla, CA). The targeting gene was the fla $\mathrm{B}$ single copy gene [11]. The $\operatorname{TaqMan}^{\mathrm{TM}}$ MGB-probe and corresponding primers were designed using Primer Express ${ }^{\mathrm{TM}}$ software (Applied Biosystems, Foster City, CA). The upstream primer was 5'-GTG CAT TTG GTT ATA TTG AG-3', the downstream primer was $5^{\prime}$-CAG ACA GAG GTT CTA TAC A-3' and the probe was FAM-5'AAT AGA GCA ACT TAC AGA-3'-MGB. The probe was purchased from Applied Biosystems and the primers were from Shanghai Shenggong (Shanghai, China).

For quantitation of the mouse host, $\beta$-actin was chosen. The upstream primer was 5'-AGA GGG AAA TCG TGC GTG AC-3', the downstream primer was 5'-
CAA TAG TGA TGA CCT GGC CGT-3' and the $\operatorname{TaqMan}^{\text {TM }}$ probe was FAM-5'CAC GGC CGC ATC CTC TTC TTC C-BHQ1-3'.

The plasmids containing the fla $\mathrm{B}$ gene of $B$. burgdorferi $\mathrm{B} 31$ and mouse $\beta$-actin gene served as standards. The plasmid containing 1100 bp flaB gene was obtained by PCR amplification using the flaB upstream primer 5' -ATG ATT ATC AAT CAT AAT ACA TCA-3' and downstream primer $5^{\prime}$-TTA TCT AAG CAA TGA CAA-3'. The PCR fragment was cloned into the pGEM$\mathrm{T}$ vector (Promega, Madison, WI) and then propagated in competent Escherichia coli JM109 (TaKaRa, Dalian, China). The plasmid containing the $129 \mathrm{bp} \beta$-actin gene was obtained by PCR amplification using the upstream primer 5'-AGA GGG AAA TCG TGC GTG AC-3' and the downstream primer 5'-CAA TAG TGA TGA CCT GGC CGT-3' and cloned as described above. Plasmid DNA was quantified using a model 2000 spectrophotometer (NanoDrop Technologies, Wilmington, DE). The plasmid control in the real-time PCR was to ensure the efficacy of the assay and to compile standard curves for determination of the flaB copy number in mouse tissue. Ten-fold serial plasmid dilutions were prepared, ranging from $10^{0}-10^{7}$ copies.

The PCR mixture (25 $\mu$ l total volume) consisted of $300 \mathrm{nM}$ primer, $200 \mathrm{nM}$ probe, $200 \mathrm{nM}$ deoxynucleoside triphosphates, $3.5 \mathrm{mM} \mathrm{MgCl} 2,2 \mu \mathrm{l}$ DNA, $1 \mathrm{U}$ AmpliTaq Gold and $1 \times$ PCR buffer. Amplification and detection were performed using 40 cycles $95^{\circ} \mathrm{C}$ for $10 \mathrm{~s}, 57^{\circ} \mathrm{C}$ for $30 \mathrm{~s}($ fla $\mathrm{B})$ and $95^{\circ} \mathrm{C}$ for $10 \mathrm{~s}$ and $60^{\circ} \mathrm{C}$ for $30 \mathrm{~s}(\beta$-actin). Actin and flaB PCR used separate reaction mixtures. The FAM signal was standardized to the passive reference ROX, which was included in the reaction buffer. Individual samples were run in triplicate.

\section{Histopathologic analysis}

On days 30, 60 and 90 after infection, three mice in each group (total 12) were sacrificed. Brain, heart, lung, liver, kidney, spleen and joint tissues were obtained and immersed in formalin. Tissues were embedded in paraffin, sectioned at a thickness of $5 \mu \mathrm{m}$ and stained with hematoxylin and eosin (H\&E). Each histopathologic parameter was assessed and scored separately by two pathologists using a semi-quantitative criteria-based scoring method [12]. Scores of 0 (absent,-), 0-10 (mild,+), 10-20 (moderate,++) and 20-30 (severe, +++ ) were assigned to each parameter, and the average scores were used to reflect the overall severity for each group of mice.

\section{Statistical analysis}

Quantitative data obtained by real-time PCR were analyzed using Prism and Excel 97 software. Significant differences were determined by unpaired Student's t test 
Table 1 Spirochete burden in blood infected by different strains at different times post-infection (p.i.) ${ }^{a}$

\begin{tabular}{lllll}
\hline Time p.i & B31 & SZ & BO23 & Control \\
\hline $2 d$ & 263 & 153 & 278 & 0 \\
$5 d$ & 329 & 105 & 558 & 0 \\
$9 d$ & 1260 & 160 & 1060 & 0 \\
$15 d$ & 258 & 875 & 250 & 0 \\
$30 d$ & 366 & 759 & 136 & 0 \\
$60 d$ & 144 & 129 & 89 & 0 \\
$90 d$ & 0 & 0 & 0 & 0 \\
\hline
\end{tabular}

a BALB/c mice were sacrificed at various time points after infection. The blood was tested for Borrelia by qPCR. The mean numbers of spirochetes per $10^{6}$ mouse cells (calculated on the basis of $\beta$-actin standard curves) are given. days (d).

implemented in Prism software, with $\mathrm{p}<0.05$ considered statistically significant.

\section{Ethical approval}

The animal experiments in this research were approved by Gansu Provincial Science and Technology department in China and in accordance with the Animal House of Lanzhou Veterinary Research Institute Instructions. The license No: SYXK2010-0001.

\section{Results}

\section{Detection and quantification of $B$. burgdorferi in mouse} tissues

Two microliters of mouse DNA or external standard template containing $10^{0}-10^{7}$ copies of B. burgdorferi fla $\mathrm{B}$ were used. Therefore, the theoretical number of bacteria in our sample was 100 times lower. All mice infected with B31 and SZ became B. burgdorferi positive, whereas B. afzelii BO23 failed to establish an infection. Spirochetes in the blood, brain, tongue, heart, lung, liver, spleen, kidney, lymph, bladder, joint and skin tissues were collected from mice infected with $B$. burgdorferi B31, B. afzelii BO23 and B. garinii SZ 2, 5, 9, 15, 30, 60, 90 and 150 days after infection (Additional file 1: Table
S1 and Table 1). Spirochete DNA was detected by qPCR in all tissues according to time course during infection; the overall patterns of bacterial load followed a fluctuated trend among the isolates during the 30 days after infection. For mice infected with B. burgdorferi B31, a relatively higher spirochete burden in tissues was reached at 2 days after infection, peaking on day 5 , gradually subsiding from days 5 to 9 and then gradually recovering from day 15 to day 30 (Figure 1A). B. garinii SZ numbers were greater at day 5 , peaked at day 9 , and gradually subsided through day 15 (Figure 1B). On day 30 after infection, $B$. burgdorferi B31 produced the more consistent and higher spirochete burden than SZ. Sixty days after infection, the differences in the numbers of spirochetes between tissues from the two Borrelia genospecies strains became smaller but the persistent tissue tropism was significantly different. On days 90 and 150 after infection, persistence of Borrelia was evident in spleens of B31 infected mice and in livers of SZ infected mice (Additional file 1: Table S1). The number of spirochetes in blood was lower compared with other tissues at the indicated times (Table 1).

\section{Severity of disease assessed by histopathologic analysis}

Histopathology of mice infected with B. burgdorferi B31, B. garinii SZ and B. afzelii BO23 on days 30, 60 and 90 after infection was studied. The differences in disease severity between B31 and SZ infected mice were significant in brain, heart, liver and spleen tissues $(\mathrm{p}<0.05)$ 30 days after infection (Table 2, Figure 2). No significant pathologic abnormality was observed in $\mathrm{BO} 23$ infected mice and no pathologic abnormality was observed in any tissues of control mice.

\section{Discussion}

There are at least five Borrelia genotypes (B. burgdorferi s.s, B. garinii, B. afzelii, B. valaisiana and B. sinica) in China, and B. burgdorferi s.s, B. garinii and B. afzelii have been reported as the main pathogenic genotypes
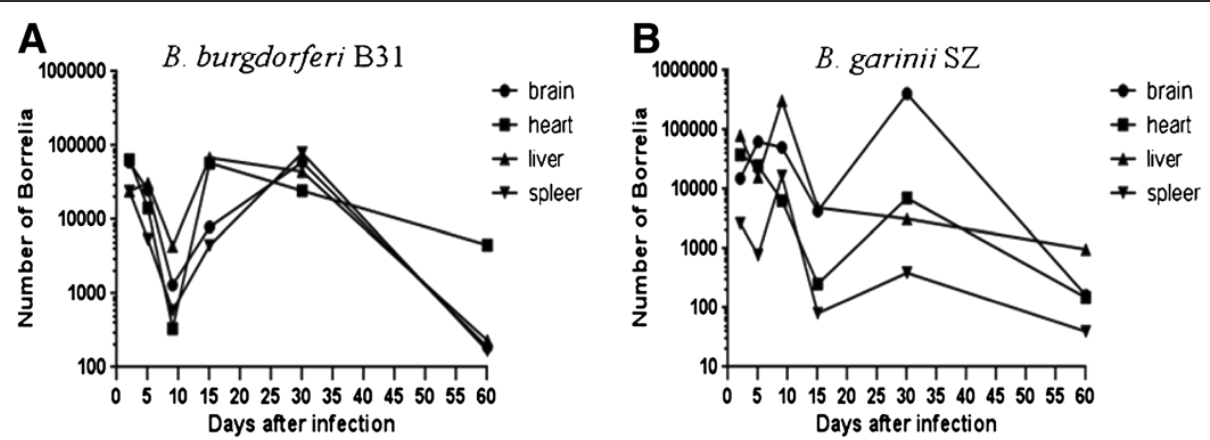

Figure 1 Kinetic distribution of spirochetes in tissues of mice. BALB/C mice were sacrificed at various time points after infection. The brain, heart, liver and spleen tissues were tested for Borrelia by qPCR. (A): B. burgdorferi B31 and (B): B. garinii SZ. The mean numbers of spirochetes per $10^{6}$ mouse cells (calculated on the basis of $\beta$-actin standard curves) are given. 
Table 2 Severity of tissue damage caused by different Borrelia strains a

\begin{tabular}{|c|c|c|c|c|c|c|c|c|}
\hline & \multicolumn{3}{|c|}{ Day 30 after infection } & \multicolumn{2}{|c|}{ Day 60 after infection } & \multicolumn{2}{|c|}{ Day 90 after infection } & \multirow[b]{2}{*}{ Control } \\
\hline & B31 & SZ & BO23 & B31 & SZ & B31 & SZ & \\
\hline Brain & ++ & +++ & - & ++ & ++ & + & ++ & - \\
\hline Heart & ++ & +++ & - & ++ & ++ & + & ++ & - \\
\hline Lung & ++ & ++ & - & + & + & + & + & - \\
\hline Liver & +++ & ++ & - & +++ & ++ & +++ & + & - \\
\hline Spleen & +++ & ++ & - & ++ & ++ & ++ & ++ & - \\
\hline Kidney & +++ & +++ & - & +++ & ++ & ++ & + & - \\
\hline Joint & ++ & ++ & - & + & + & + & - & - \\
\hline
\end{tabular}

a +++ severe, ++ moderate, + mild, -absent.

Three mice in each group were sacrificed at 30,60, and 90 days after inoculation. Disease severity was assessed by histopathologic assessment of inflammatory cell infiltrates and necrosis extent in tissues. The differences in disease severity between B31 and SZ infected mice were significant in brain, heart, liver and spleen tissues $(P<0.05)$ at 30 days after inoculation. At 60 and 90 days after inoculation, there were varying degrees of recovery.

of humans and animals [13]. B. garinii is the main genotype in China [9]. B. garinii SZ isolated from Dermacentor ticks collected in Shangzhi County of Heilongjiang Province in China is very similar to B. garinii strain DK27 isolated from Denmark and B. garinii Khab isolated from France in terms of the morphology and molecular characteristics [10]. As the presence of $B$. burgdorferi species in Dermacentor ticks has been widely noted, but vector competence appears to be very poor [14]. When B. burgdorferi B31 low passage strain spirochetes were directly injected into the hemocoel of Dermacentor variabilis, the bacteria were cleared early [15]. However, the occasional human cases of Lyme disease in Indiana were observed from Dermacentor variabilis ticks [16] and the epidemiology of tickborne pathogens infecting Dermacentor spp. in France has been reported [17]. Hence, they are often omitted from the Dermacentor tick investigations. The present study assessed the pathogenicity of $B$. garinii $\mathrm{SZ}$ in a murine model.

Evidence from real-time PCR and histopathology indicated that B. burgdorferi B31 and B. garinii SZ could disseminate to different interior tissues 2 days after infection. This is inconsistent with the previously reported findings in $\mathrm{C} 3 \mathrm{H}$ and $\mathrm{BALB} / \mathrm{c}$ mice infected with $B$. burgdorferi B31, in which the bacteria were initially detected in organs 8-15 days after infection [7,18]. Dissemination of the bacteria as early as 2 days after experimental infection in mice has been reported [19]. This difference can be attributed to the routes of infection, host factors and detection methods of the bacterial burden $[20,21]$. The presence of Borrelia in target tissues and consequent interactions with the host play a role in promoting host inflammation and affect the clinical presentation of disease [12]. Presently, differences in disease severity between B. burgdorferi B31 and B. garinii SZ infected mice were significant in brain, heart, liver and spleen tissues at 30 days after inoculation. The difference in the clinical manifestation was highly correlated with the difference of the spirochete burden. This phenomenon was also observed by other authors [18]. In B31 infected mice, spirochetes persisted in the kidney. In SZ infected mice, spirochetes persisted in the liver and spleen. These findings might provide a reference for epidemiological investigation of the field samples. The present observation of infections lasting up to 6 months was consistent with prior results [22].

Although bloodstream invasion is an important route, evidence from the real-time PCR indicated that blood spirochete burden in mice infected with the three genospecies of Borrelia strains was low. A previous study used a nested and quantitative polymerase chain

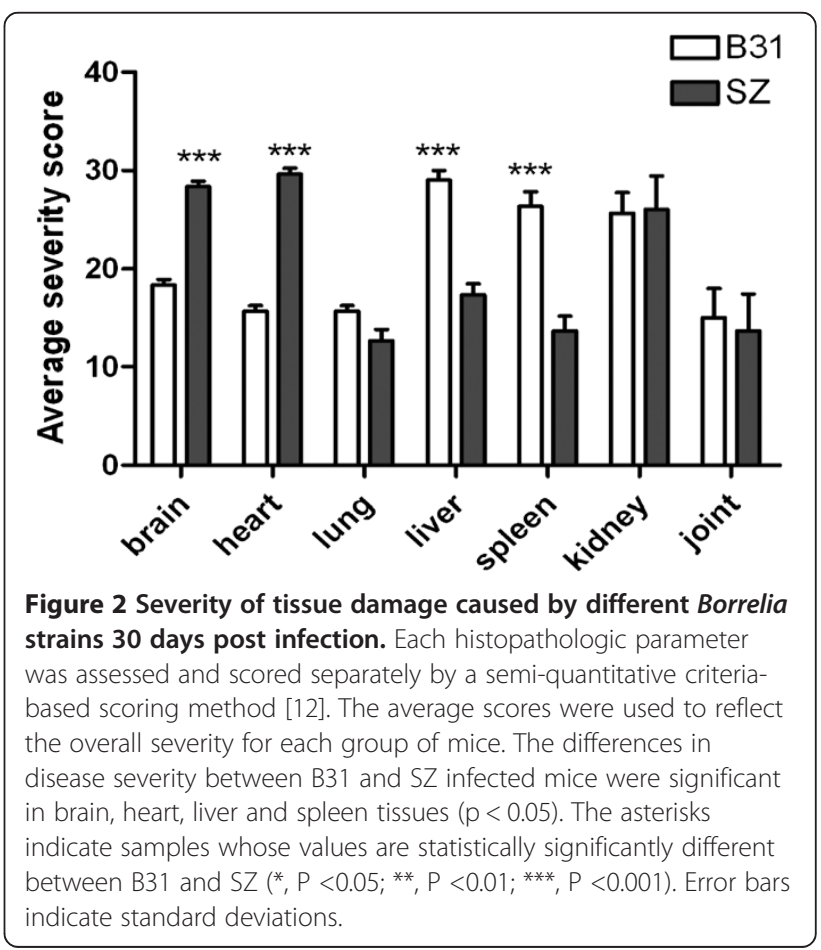


reaction (qPCR) to detect cell associated flaB gene DNA in the plasma of untreated early Lyme disease patients with erythema migrans; the number of fla $\mathrm{B}$ gene copies did not significantly correlate with any of the clinical, demographic or laboratory variables assessed (8), which may be an important factor in explaining why some spirochetemic patients are completely asymptomatic [23]. However, another study reported that the bacterial burden in blood was significantly correlated with disease severity [12], with the peak number observed 4-7 days after infection. This may explain why some infected patients have only subclinical disease, whereas others develop overt manifestations.

Signs and symptoms of putative failure of BO23 infection in mice or ineffectiveness of infection with $\mathrm{BO} 23$ may be formally attributed to the mouse species; it is possible that not all species of mice are susceptible to disseminated infection by $B$. burgdorferi isolates. Variable host susceptibility to different $B$. burgdorferi isolates and complement sensitivity among different Borrelia species has been reported [24].

\section{Conclusions}

The present study aimed to determine the pathogenicity of B. garinii SZ, in which B. burgdorferi B31 and $B$. afzelii $\mathrm{BO} 23$ were used for comparison. The data obtained by real-time PCR and the histopathology indicated the correlations of spirochete burden and disease severity in mouse tissues in infections caused by $B$. garinii SZ, B. burgdorferi $\mathrm{B} 31$ and B. afzelii BO23. The $B$. garinii SZ strain is highly pathogenic and can trigger multi-system pathological damage in mice. Ninety days after infection, the differences in spirochete burden were evident in terms of the persistence and tissue tropism. Infections could persist up to 6 months.

Further studies using experimental infections and transmission with additional clinical isolates may be conducted to analyze vector competency of Dermacentor spp. for this pathogen and to clarify the potential role of genotypic variation of $B$. burgdorferi in the pathogenicity of Lyme disease.

\section{Additional file}

Additional file 1: Table S1. MGB-probe based quantitative real time PCR for simultaneous detection and quantification of $B$. burgdorferi in different tissues of BALB/C mice*.

Competing interests

The authors declare that they have no competing interest.

\section{Authors' contributions}

QW designed the experimental. QW and JW carried out most of the experiments. YL, GG, JY and ZC participated in the design of the study and helped experimental development. QW and ZL drafted the manuscript. J and HY conceived, coordinated and provided financial support for the study. All authors have read and approved the final version of the manuscript.

\section{Acknowledgments}

This study was financially supported by the "973" Program (2010CB530206), NSFC (31272556, 30972182, 31072130, 31001061), "948" (2010-S04), Key Project of Gansu Province (1002NKDA035), NBCITS.MOA (CARS-38), Specific Fund for Sino-Europe Cooperation, MOST, China, State Key Laboratory of Veterinary Etiological Biology Project (SKLVEB2008ZZKT019). The research was also facilitated by EPIZONE (FOOD-CT-2006-016236), ASFRISK (211691), ARBOZOONET (211757) and PIROVAC (KBBE-3-245145) of the European Commission, Brussels, Belgium.

Received: 5 May 2013 Accepted: 13 June 2013

Published: 17 June 2013

\section{References}

1. Stanek G, Reiter M: The expanding Lyme Borrelia complex-clinical significance of genomic species? Clin Microbiol Infect 2011, 17(4):487-493.

2. Rudenko N, Golovchenko M, Růzõek D, Piskunova N, Mallatova N, Grubhoffer L: Molecular detection of Borrelia bissettii DNA in serum samples from patients in the Czech Republic with suspected borreliosis. FEMS 2009, 292(2):274-281

3. Scholz HC, Margos G, Derschum H, Speck S, Tserennorov D, Erdenebat N, Undraa B, Enkhtuja M, Battsetseg J, Otgonchimeg C: High prevalence of genetically diverse Borrelia bavariensis-like strains in Ixodes persulcatus from Selenge Aimag, Mongolia. Ticks Tick Borne Dis 2013, 4(1-2):89-92.

4. Wilske B, Busch U, Eiffert H, Fingerle V, Pfister HW, Rössler D, Preac-Mursic V: Diversity of OspA and OspC among cerebrospinal fluid isolates of Borrelia burgdorferi sensu lato from patients with neuroborreliosis in Germany. Med Microbiol Immunol 1996, 184(4):195-201.

5. Canica MM, Nato F, Merle L, Mazie JC, Baranton G, Postic D: Monoclonal antibodies for identification of Borrelia afzelii sp. nov. associated with late cutaneous manifestations of Lyme borreliosis. Scand J Infect Dis 1993, 25(4):441-448

6. Lünemann JD, Zarmas S, Priem S, Franz J, Zschenderlein R, Aberer E, Klein R, Schouls L, Burmester GR, Krause A: Rapid typing of Borrelia burgdorferisensu lato species in specimens from patients with different manifestations of Lyme borreliosis. J Clin Microbiol 2001, 39(3):1130-1133.

7. Pahl A, Kühlbrandt U, Brune K, Röllinghoff M, Gessner A: Quantitative detection of Borrelia burgdorferi by real-time PCR. J Clin Microbiol 1999, 37(6):1958-1963.

8. Wormser GP, Liveris D, Nowakowski J, Nadelman RB, Cavaliere LF, McKenna D, Holmgren D, Schwartz I: Association of specific subtypes of Borrelia burgdorferi with hematogenous dissemination in early Lyme disease. J Infect Dis 1999, 180(3):720-725.

9. Hao Q, Hou X, Geng Z, Wan K: Distribution of Borrelia burgdorferi sensu lato in China. J Clin Microbiol 2011, 49(2):647-650.

10. Niu Q, Yang J, Guan G, Fu Y, Ma M, Li Y, Liu J, Liu Z, Liu A, Ren Q: Identification and phylogenetic analysis of Lyme disease Borrelia spp. isolated from Shangzhi Prefecture of Heilongjiang Province. Chinese Veterinary Science 2010, 40:551-556.

11. Fraser CM, Casjens S, Huang WM, Sutton GG, Clayton R, Lathigra R, White $O$, Ketchum KA, Dodson R, Hickey EK: Genomic sequence of a Lyme disease spirochaete, Borrelia burgdorferi. Nature 1997, 390(6660):580-586.

12. Wang G, Ojaimi C, Wu H, Saksenberg V, lyer R, Liveris D, McClain SA, Wormser GP, Schwartz I: Disease severity in a murine model of Lyme borreliosis is associated with the genotype of the infecting Borrelia burgdorferi sensu stricto strain. J Infect Dis 2002, 186(6):782-791.

13. Niu Q, Yin H, Luo J: Progress on Lyme disease in China. Progress in Veterinary Medicine 2009, 30:89-93.

14. Dolan MC, Maupin GO, Panella NA, Golde WT, Piesman J: Vector competence of Ixodes scapularis, I. spinipalpis, and Dermacentor andersoni (Acari: Ixodidae) in transmitting Borrelia burgdorferi, the etiologic agent of Lyme disease. J Med Entomol 1997, 34(2):128-135.

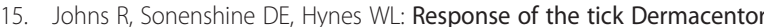
variabilis (Acari: Ixodidae) to hemocoelic inoculation of Borrelia burgdorferi (Spirochetales). J Med Entomol 2000, 37(2):265-270.

16. Ritter MM: Lyme disease in Indiana: isolation of Borrelia burgdorferi-like organisms from Dermacentor variabilis. Ball State University. Dept. of Biology -- Theses (D. Ed.); 1987:1-70 
17. Bonnet S, de la Fuente J, Nicollet P, Liu X, Madani N, Blanchard B, Maingourd C, Alongi A, Torina A, Fernández de Mera I: Prevalence of tickborne pathogens in adult dermacentor spp. Ticks from nine collection sites in France. Vector Borne Zoonotic Dis 2013, 13(4):226-236.

18. Wang G, Ojaimi C, lyer R, Saksenberg V, McClain SA, Wormser GP, Schwartz I: Impact of genotypic variation of Borrelia burgdorferi sensu stricto on kinetics of dissemination and severity of disease in $\mathrm{C} 3 \mathrm{H} / \mathrm{HeJ}$ mice. Infect Immun 2001, 69(7):4303-4312.

19. Barthold SW, Persing DH, Armstrong A, Peeples RA: Kinetics of Borrelia burgdorferi dissemination and evolution of disease after intradermal inoculation of mice. Am J Pathol 1991, 139(2):263.

20. Pennington PM, Allred CD, West CS, Alvarez R, Barbour AG: Arthritis severity and spirochete burden are determined by serotype in the Borrelia turicatae-mouse model of Lyme disease. Infect Immun 1997, 65(1):285-292.

21. Brown CR, Reiner $S L$ : Genetic control of experimental Lyme arthritis in the absence of specific immunity. Infect Immun 1999, 67(4):1967-1973.

22. Stanek G, Fingerle V, Hunfeld KP, Jaulhac B, Kaiser R, Krause A, Kristoferitsch W, O'Connell S, Ornstein K, Strle F: Lyme borreliosis: clinical case definitions for diagnosis and management in Europe. Clin Microbiol Infect 2011, 17(1):69-79.

23. Wormser GP: Hematogenous dissemination in early Lyme disease. Wien Klin Wochenschr 2006, 118(21):634-637.

24. Gern L, Estrada-Pena A, Frandsen F, Gray J, Jaenson T, Jongejan F, Kahl O, Korenberg E, Mehl R, Nuttall P: European reservoir hosts of Borrelia burgdorferi sensu lato. Zentralbl Bakteriol 1998, 287(3):196-204.

doi:10.1186/1756-3305-6-177

Cite this article as: Wu et al:: Pathogenic analysis of Borrelia garinii strain SZ isolated from northeastern China. Parasites \& Vectors 2013 6:177.

\section{Submit your next manuscript to BioMed Central and take full advantage of:}

- Convenient online submission

- Thorough peer review

- No space constraints or color figure charges

- Immediate publication on acceptance

- Inclusion in PubMed, CAS, Scopus and Google Scholar

- Research which is freely available for redistribution 